\title{
Sodium butyrate protects mice from the development of the early signs of non-alcoholic fatty liver disease: role of melatonin and lipid peroxidation
}

\author{
Cheng Jun Jin ${ }^{1}$, Anna Janina Engstler ${ }^{1}$, Cathrin Sellmann ${ }^{1}$, Doreen Ziegenhardt ${ }^{1}$, Marianne Landmann ${ }^{1,3}$, \\ Giridhar Kanuri $^{1,4}$, Hakima Lounis ${ }^{1,5}$, Markus Schröder ${ }^{2}$, Walter Vetter ${ }^{2}$ and Ina Bergheim ${ }^{1,6_{*}}$ \\ ${ }^{1}$ Institute of Nutritional Sciences, SD Model Systems of Molecular Nutrition, Friedrich-Schiller-University, O7743 Jena, Germany \\ ${ }^{2}$ Institute of Food Chemistry, University of Hohenheim, 70599 Stuttgart, Germany \\ ${ }^{3}$ Department of Nutritional Sciences, Applied Nutritional Sciences, Friedrich-Schiller-University Jena, O7743 Jena, Germany \\ ${ }^{4}$ St. John's National Academy of Health Sciences, Bangalore, 560034, Karnataka State, India \\ ${ }^{5}$ Department of Physical-Chemistry Biology, Faculty of Nature and Life Sciences, A. Mira, University, Béjaïa, O6000 Algeria \\ ${ }^{6}$ Department of Nutritional Sciences, Molecular Nutritional Science, University of Vienna, A-1090 Vienna, Austria
}

(Submitted 25 April 2016 - Final revision received 22 September 2016 - Accepted 25 October 2016)

\section{Abstract}

Non-alcoholic fatty liver disease (NAFLD) is one of the most common liver diseases worldwide with universally accepted treatments still lacking. Oral supplementation of sodium butyrate ( $\mathrm{SoB}$ ) has been suggested to attenuate liver damage of various aetiologies. Our study aimed to further delineate mechanisms involved in the SoB-dependent hepatic protection using a mouse model of fructose-induced NAFLD and in in vitro models. C57BL $/ 6 \mathrm{~J}$ mice were either pair-fed a fructose-enriched liquid diet $\pm 0.6 \mathrm{~g} / \mathrm{kg}$ body weight per $\mathrm{d}$ SoB or standard chow for 6 weeks. Markers of liver damage, intestinal barrier function, glucose metabolism, toll-like receptor-4 (TLR-4) and melatonin signalling were determined in mice. Differentiated human carcinoma colon-2 (Caco-2) and J774A.1 cells were used to determine molecular mechanisms involved in the effects of SoB. Despite having no effects on markers of intestinal barrier function and glucose metabolism or body weight gain, SoB supplementation significantly attenuated fructose-induced hepatic TAG accumulation and inflammation. The protective effects of SoB were associated with significantly lower expression of markers of the TLR-4-dependent signalling cascade, concentrations of inducible nitric oxide synthase (iNOS) protein and 4-hydroxynonenal protein adducts in liver. Treatment with SoB increased melatonin levels and expression of enzymes involved in melatonin synthesis in duodenal tissue and Caco-2 cells. Moreover, treatment with melatonin significantly attenuated lipopolysaccharide-induced expression of iNOS and nitrate levels in J774A.1 cells. Taken together, our results indicated that the protective effects of SoB on the development of fructose-induced NAFLD in mice are associated with an increased duodenal melatonin synthesis and attenuation of iNOS induction in liver.

Key words: Non-alcoholic fatty liver disease: Sodium butyrate: Inducible nitric oxide synthase: Melatonin

By now, non-alcoholic fatty liver disease (NAFLD) is accounted to be among the most common liver disease worldwide ${ }^{(1)}$. Ranging from simple hepatic steatosis without inflammation to non-alcoholic steatohepatitis, fibrosis and to even cirrhosis and hepatocellular carcinoma, NAFLD encompasses a wide spectrum of disease stages ${ }^{(2,3)}$. Results of our group but also of others suggest that besides a general overnutrition and genetic predisposition, alterations at the level of gut, for example alterations of intestinal microbiota and intestinal barrier function subsequently leading to an increased permeation of bacterial endotoxin and elevated endotoxin levels, may be critical factors in the development and progression of NAFLD ${ }^{(4-7)}$. However, despite intensive research efforts, molecular mechanisms involved in the development and progression of NAFLD remain unclear and except life-style modifications such as energyrestricted diets and increase of physical activity, efficient treatment and prevention strategies are still lacking.

In humans, the SCFA butyrate, shown to be essential for nourishing intestinal epithelial cells, is mainly produced by intestinal micro-organisms ${ }^{(8)}$. Furthermore, animal studies suggest that butyrate and micro-organisms synthesising butyrate possess beneficial effects on the development of liver injuries of various aetiologies through improvement of intestinal barrier function $^{(9,10)}$. In line with these findings, results of Mattace et $a{ }^{(11)}$ suggest that sodium butyrate (SoB) and its synthetic derivative $N$-(1-carbamoyl-2-phenyl-ethyl) butyramide may

Abbreviations: Caco-2, human carcinoma colon-2; FD, fructose-enriched liquid diet; HIOMT, hydroxyindole-O-methyltransferase; iNOS, inducible nitric oxide synthase; LPS, lipopolysaccharide; MT, melatonin receptor; NAFLD, non-alcoholic fatty liver disease; PAI-1, plasminogen activator inhibitor-1; SoB, sodium butyrate; SOD, superoxide dismutase; TLR-4, toll-like receptor 4; ZO-1, zonula occludens 1.

* Corresponding author: I. Bergheim, email ina.bergheim@univie.ac.at 
attenuate liver steatosis and inflammation in rats fed a high-fat diet. In addition, results of recent animal studies indicate that treatment with SoB may improve intestinal permeability and reduce serum endotoxin levels, as well as inflammatory cytokines, shown to be involved in the development of liver diseases induced through ingestion of toxins and certain diets, respectively $^{(9,12,13)}$. Our own group recently showed that oral ingestion of SoB markedly protected mice from the development of a Western-style diet (WSD)-induced NAFLD ${ }^{(14)}$. In this study, protective effects were not associated with a protection against the loss of tight-junction proteins in the small intestine but rather with an attenuation of lipid peroxidation and protection against the induction of inducible nitric oxide synthase (iNOS) in livers of mice ${ }^{(14)}$. However, molecular mechanisms involved in the beneficial effects of the oral supplementation of SoB are not yet fully understood.

Using a mouse model of feeding a fructose-enriched diet to induce early stages of NAFLD but also differentiated human carcinoma colon-2 (Caco-2) cells as a model of enterocytes and J774A.1 cells as a model of hepatic Kupffer cells, the aim of the present study was to further delineate molecular mechanism involved in the protective effects of an oral supplementation of SoB on the development of NAFLD.

\section{Methods \\ Animals and treatments}

In total, 12-week-old male C57BL/6J mice (Janvier SAS) were housed in a pathogen-free barrier facility accredited by the Association for Assessment and Accreditation of Laboratory Animal Care. All the procedures were approved by the local Institutional for Animal Care and Use Committee. During a 6-week feeding period, mice ( $n$ 6/group) were pair-fed (isoenergetic) either a fructose-enriched liquid diet $(55 \%$ of total energy intake from fructose, FD) or a fructose-enriched diet supplemented with $0.6 \mathrm{~g} / \mathrm{kg}$ body weight (Sigma-Aldrich). Isoenergetic pair-feeding of mice in the fructose groups was achieved as detailed in Sellmann et al. ${ }^{(15)}$. In brief, intake of the liquid diets was assessed daily within groups, and amount of diet fed was adjusted accordingly among groups for the next day. In addition, naïve mice serving as controls were fed standard pellet chow (Ssniff). Details of diets fed are shown in the online Supplementary Table S1. All mice had free access to plain tap water, and body weight of mice was measured weekly. In week 4 , mice were fasted for $6 \mathrm{~h}$ and blood samples were collected from the retrobulbar venous plexus to determine fasting blood glucose and insulin levels (Hölzel diagnostics). Homoeostasis model assessment for insulin resistance (HOMA-IR) index was calculated using the formula HOMA-IR = fasting blood glucose $(\mathrm{mg} / \mathrm{dl}) \times$ fasting insulin concentration $(\mathrm{mU} / \mathrm{l}) / 405$, as previously detailed $^{(16)}$. After 6 weeks, mice were anaesthetised with $100 \mathrm{mg}$ ketamin/kg and $16 \mathrm{mg}$ xylazin/kg body weight by intraperitoneal injection. Blood from portal vein was collected just before they were killed. Tissue samples of liver and intestine were either fixed in O.C.T medium (Medite), neutral-buffered formalin or shock-frozen in liquid $\mathrm{N}_{2}$. Samples were then kept in a $-80^{\circ} \mathrm{C}$ freezer until further measurements.

\section{Histological evaluation of liver and goblet cell staining} in duodenum sections

Frozen liver sections $(10 \mu \mathrm{m})$ were stained with Oil red O (Sigma-Aldrich), as described previously ${ }^{(17)}$. Liver sections $(5 \mu \mathrm{m})$ embedded in paraffin were stained with haematoxylineosin (Sigma-Aldrich) to evaluate the histologic features as detailed before ${ }^{(14)}$. To determine goblet cell number being indicative of mucous formation ${ }^{(18)}$, duodenal sections $(4 \mu \mathrm{m})$ embedded in paraffin were consecutively stained with Alcian blue $(30 \mathrm{~min})$, periodic acid $(10 \mathrm{~min})$, Schiff's reagent (15 min) (all from Carl-Roth) and counterstained with haematoxylin. Quantitative evaluation of staining was carried out as previously described in detail ${ }^{(19)}$. Representative photomicrographs of Oil Red $O(100 \times)$ and haematoxylin-eosin $(200 \times)$, as well as goblet cell $(200 \times)$ staining, were captured using the system incorporated in the microscope (Leica DM4000 B LED).

\section{Hepatic TAG determination and clinical chemistry}

Hepatic TAG were isolated as described in detail previously ${ }^{(17)}$. TAG levels were determined by using a commercially available kit (Randox). Fasting blood glucose was determined using a blood glucose meter (Contour; Bayer Vital GmbH). Alanine aminotransferase (ALT) activity was determined using a commercially available kit (Randox).

\section{Endotoxin assay}

Portal plasma samples were heated at $70^{\circ} \mathrm{C}$ for $20 \mathrm{~min}$ before the measurement. Levels of endotoxin were then determined using a commercially available limulus amebocyte lysate assay with a concentration range of $0 \cdot 15-1 \cdot 2 \mathrm{EU} / \mathrm{ml}$ (Charles River), as previously described in detail ${ }^{(20)}$.

\section{Immnohistochemical staining for liver and duodenum of mice}

Paraffin-embedded liver sections $(5 \mu \mathrm{m})$ were stained for 4-hydroxynonenal (4-HNE) protein adducts and iNOS using a polyclonal antibody (4-HNE: AG Scientific; iNOS: Affinity BioReagents), as described previously ${ }^{(17)}$. Paraffin-embedded duodenal sections $(4 \mu \mathrm{m})$ were stained for occludin (Invitrogen Corporation), zonula occludens 1 (ZO-1; Life Technologies $\mathrm{GmbH}$ ) and hydroxyindole-O-methyltransferase (HIOMT; Biozol Diagnostica Vertrieb $\mathrm{GmbH}$ ) using polyclonal primary antibodies, as described previously ${ }^{(17)}$. In brief, specific binding of primary antibody to the target protein was detected by incubating sections with a peroxidase-linked secondary antibody and diaminobenzidine (Peroxidase Envision Kit; Dako). Photos of eight fields of each tissue section $(200 \times$ of each liver tissue section; 400x of occludin staining and 200x of HIOMT staining of duodenum tissue) were captured and the extent of staining in the sections was defined as percentage of microscopic field within the default colour range determined by the analysis system incorporated in the microscope (Leica DM4000 B LED). Mean values of eight sections were used as the score of the sample. 
Table 1. Mouse and human primer sequences used for real-time RT-PCR detection

\begin{tabular}{|c|c|c|}
\hline Primers & Forward $\left(5^{\prime}-3^{\prime}\right)$ & Reverse $\left(5^{\prime}-3^{\prime}\right)$ \\
\hline \multicolumn{3}{|l|}{ Mouse } \\
\hline $18 S$ & GTA ACC CGT TGA ACC CCA TT & CCA TCC AAT CGG TAG TAG CG \\
\hline$C C L-2$ & GCC AGA CGG GAG GAA GGC CA & TGG ATG CTC CAG CCG GCA AC \\
\hline$T L R-4$ & AGC CAT TGC TGC CAA CAT CA & GCT GCC TCA GCA GGG ACT TC \\
\hline MyD88 & CAA AAG TGG GGT GCC TTT GC & AAA TCC ACA GTG CCC CCA GA \\
\hline IR & CAT CCC GAA AGC GAA GAT CC & GAG TCC TGA TTG CAT GCC TGC \\
\hline IRS-1 & GTT GCC ACC CCT AGA CAA AA & GCT CTA GTG CTT CCG TGT CC \\
\hline iNOS & CAG TGG GCT GTA SAA ACC TT & CAT TGG AAG TGA AGC GTT TCG \\
\hline MT-1 & AAT GCC ACT CAG CAG GCT CCA G & AGC AGG TTG CCC AGA ATG TCC A \\
\hline MT-2 & AGG GCT ACC GTG CCT GTC AA & AGG TTT GCT GCT AGG CCC ACT \\
\hline$\angle B P$ & GGT GGC GTG GTC ACT AAT GT & CTC ACT TGT GCC TTG TCT GG \\
\hline \multicolumn{3}{|c|}{ 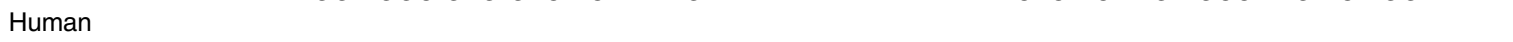 } \\
\hline $18 S$ & GGC CTC GAA AGA GTC CTG TAT TGT T & TCT GCC CTA TCA ACT TTC GAT GGT A \\
\hline MT-2 & AAT GAG GAA AGG CCT GGG GCA & CCC ACC TGA GGC CCT TGC AGT TA \\
\hline HIOMT & TAG GGC AAC GGC TTC ATG GT & CAG CAG CTT CAG GGA CAC ACA G \\
\hline
\end{tabular}

\section{RNA isolation and real-time RT-PCR}

Total RNA from liver tissue, differentiated Caco-2 cells and J774A.1 cells was isolated using peqGOLD TriFast ${ }^{\mathrm{TM}}$ (PEQLAB), and real-time RT-PCR was carried out as detailed by Jin et al. ${ }^{(21)}$ and Wagnerberger et al. ${ }^{(22)}$. PCR primers for determining melatonin receptor (MT) 2, HIOMT, $18 S$ in human cells, for example Caco-2 cells and PCR primers used to measure expression of chemokine (C-C motif) ligand 2 (CCL-2), toll-like receptor $4(T L R-4)$, myeloid differentiation primary response gene 88 (MyD88), insulin receptor (IR), insulin receptor substrate 1 (IRS-1), iNOS, lipopolysaccharide-binding protein (LBP), MT-1 and MT-2, as well as $18 S$ in mouse tissue and cell lines, were designed using Primer 3 software (Whitehead Institute for Biomedical Research). Primer sequences are shown in Table 1. SYBR Green ${ }^{\circledR}$ Supermix (Agilent Technologies) was used to prepare the PCR mix. The comparative cycle threshold $\left(C_{t}\right)$ method was used to determine the amount of target, normalised to an endogenous reference and relative to a calibrator $\left(2^{\Delta \Delta C_{t}}\right)$. The purity of the PCR products was verified by melting curves and gel electrophoresis.

\section{ELISA}

Concentrations of TNF- $\alpha$, plasminogen activator inhibitor-1 (PAI-1) and superoxide dismutase (SOD)-1 activity in the liver tissue were determined using commercially available kits (TNF- $\alpha$ : AssayPro; PAI-1: LOXO GmbH; SOD activity: Enzo Life Science). Levels of melatonin in duodenum and in cell culture medium were determined with the ELISA kit (IBL International $\mathrm{GmbH})$.

\section{Sodium butyrate determination in mouse plasma}

Plasma $(15 \mu \mathrm{l}), 15 \mu \mathrm{l}$ of the internal standard $n$-valeric acid $(0.010 \mathrm{mg} / \mathrm{ml}$ in water; Sigma-Aldrich) and $300 \mu \mathrm{l}$ of $n$-propanol with $1 \% \mathrm{H}_{2} \mathrm{SO}_{4}$ (both from BASF) were combined in a 6-ml tube and incubated at $80^{\circ} \mathrm{C}$ for $1 \mathrm{~h}$. $n$-Hexane $(500 \mu$; Th.Geyer $)$ and $\mathrm{H}_{2} \mathrm{O}(3 \mathrm{ml})$ were added and the tube was shaken. After phase separation, the lower water phase was removed, and the organic phase was washed with $3 \mathrm{ml}$ of $\mathrm{H}_{2} \mathrm{O}$. An aliquot $(200 \mu \mathrm{l})$ was amended with the second internal standard butyric acid butyl ester and the sample was analysed by GC with electron ionisation MS operated in selected ion monitoring mode using an Rtx-2330 column ( $60 \mathrm{~m}, 10 \%$ cyanopropylphenyl and $90 \%$ biscyanopropyl polysiloxane; Restek; internal diameter: $0.25 \mathrm{~mm}$; film thickness: $0 \cdot 1 \mu \mathrm{m}$ ) and helium (quality: 5.0; Sauerstoffwerk) as the carrier gas. After a solvent delay of $7 \mathrm{~min} \mathrm{~m} / z 71, \mathrm{~m} / z$ 85, $\mathrm{m} / z$ 89, $\mathrm{m} / \mathrm{z}$ $103, m / z 130$ and $m / z 144$ were analysed.

\section{Detection of nitrite}

Nitrite content in the cell culture medium was determined using a commercially available colorimetric assay (Griess Reagent System, Promega). In brief, $50 \mu$ l of each experimental cell culture medium was mixed with $100 \mu \mathrm{l}$ of Griess reagent and absorbance was measured at $550 \mathrm{~nm}$ wavelength.

\section{Cell culture and treatment}

Caco-2 cells (American Type Culture Collection) were maintained in Dulbecco's modified Eagle's medium (DMEM; PAN-Biotech $\mathrm{GmbH}$ ) and cultured as detailed previously ${ }^{(20)}$. For experiments, cells were seeded in six-well plates, and after reaching confluence they were differentiated for $9 \mathrm{~d}$. On the last day of differentiation, medium was removed and replaced with fresh medium with SoB (0-6 mm, Sigma-Aldrich) for 6-48 h. Concentrations and time points of treatment were adopted from others ${ }^{(23)}$. To determine the melatonin concentration, cell culture medium was collected. For measurement of HIOMT mRNA expression, RNA from cells was extracted as detailed in the online Supplementary Materials.

Cultured J774A.1 macrophages (mouse ascites macrophages; American Type Culture Collection) plated in six-well plates were maintained in DMEM medium supplemented with $10 \%$ fetal calf serum and $1 \%$ penicillin/streptomycin until $70 \%$ confluence was reached. Cells were preincubated with $0-1 \mathrm{~mm}$-melatonin (Sigma-Aldrich) at $37^{\circ} \mathrm{C}$ for $2 \mathrm{~h}$. Melatonin concentrations used 
were determined in pilot dose-response studies (data not shown). Then, $25 \mathrm{ng} / \mathrm{ml}$ lipopolysaccharide (LPS; Sigma-Aldrich) was added to the medium and incubation was continued for $18 \mathrm{~h}$. Medium was collected to determine nitrite concentration and cells were lysed to obtain RNA for further analysis.

\section{Statistical analysis}

Results are expressed as mean values with their standard errors. Non-parametric $t$ test was used to determine statistical differences between the two fructose-diet-treated mouse groups. One-way ANOVA with Tukey's post hoc test was used to determine the statistical differences when comparing results of cell culture experiments (GraphPad Prism version 6.0; Graph Pad Software). Outliers were identified using the Grubbs's test. $P$ value $<0.05$ was considered to be significant.

\section{Results}

\section{Plasma butyrate levels, markers of hepatic fat accumulation} and inflammation, as well as glucose metabolism

Plasma butyrate levels determined in portal plasma were similar between both FD-fed mouse groups and naïve controls (Table 2). Energy intake and body weight gain, as well as liver weight and liver:body weight ratio, were also similar between FD-fed groups (Table 2). Fasting blood glucose and insulin levels, as well as HOMA index of mice, did not differ between FD-fed groups (Table 2). However, mRNA expression of both $I R$ and IRS-1 was significantly lower in livers of mice fed FD + SoB than in those only fed the FD, which were almost at the level of naïve controls (Fig. 1). Hepatic fat accumulation as determined by assessing liver histology and measuring TAG levels in liver tissue was significantly lower in mice fed FD $+\mathrm{SoB}$ when compared with mice only fed FD (TAG: $-40 \%$ when compared with FD, $P<0.05)$. However, TAG levels in livers of mice fed $F D+S o B$ were still markedly higher than in naïve controls (Fig. 1(a)-(c)). ALT plasma activity was also markedly lower in mice fed FD + SoB when compared with mice only fed FD; however, as some samples were lost because of haemolysis and as data varied considerably within groups, differences did not reach the level of significance (Fig. 1(d)). Expression levels of $C C L-2$ mRNA and protein levels of TNF- $\alpha$ and PAI- 1 were lower in livers of mice fed FD $+\mathrm{SoB}$ when compared with mice only fed FD (Table 2) (CCL-2: approximately $-60 \%, P<0.05$; TNF- $\alpha$ : approximately $-30 \%, P<0.05$; PAI-1: approximately $-60 \%, P=0.08$, all compared with FD). Indeed, concentrations of all three inflammatory markers were almost at the level of those determined in naïve controls in livers of FD+SoB-fed mice.

Tight-junction proteins and goblet cells in duodenum and toll-like receptor 4 and myeloid differentiation primary response gene 88 mRNA expression, as well as markers of lipid peroxidation and oxidative defence in liver

Protein levels of the tight-junction proteins occludin and ZO-1, as well as numbers of goblet cells in duodenum, did not differ between the two FD-fed mouse groups. However, protein levels of both occludin and ZO-1 in the duodenum were markedly lower in both FD-fed groups than in naïve controls (Fig. 2 and online Supplementary Fig. S1(a)-(c)). In line with these findings, the endotoxin concentration in portal plasma and mRNA expression of $L B P$ in liver also did not differ between FD-fed groups but were markedly higher than in naïve controls (Fig. 3(a) and (b)). However, expression levels of both TLR-4 and MyD88 mRNA were significantly lower in livers of mice fed $\mathrm{FD}+\mathrm{SoB}$ in comparison with mice only fed FD (Fig. 3(c) and (d)). In line with these findings, protein expression levels of iNOS and 4-HNE protein adducts were also significantly lower in livers of mice fed FD + SoB when compared with those of mice only fed FD (Fig. 4(a) and (b) and online Supplementary Fig. S2). In contrast, activity of SOD-1 was significantly lower in livers of mice fed FD $+\mathrm{SoB}$ when compared with mice only fed FD (approximately $-50 \%$ ) (Fig. 4(c)).

Table 2. Effect of an oral supplementation of sodium butyrate on body weight, liver:body weight ratio and markers of liver damage, as well as markers of insulin resistance, in mice fed a fructose-enriched diet for 6 weeks (Mean values with their standard errors)

\begin{tabular}{|c|c|c|c|c|c|c|}
\hline & \multicolumn{2}{|c|}{ Control } & \multicolumn{2}{|c|}{ FD } & \multicolumn{2}{|c|}{$\mathrm{FD}+\mathrm{SoB}$} \\
\hline & Mean & SEM & Mean & SEM & Mean & SEM \\
\hline SoB in plasma $(\mu \mathrm{g} / \mathrm{ml})$ & 3.0 & 0.2 & $3 \cdot 2$ & 0.5 & $2 \cdot 8$ & 0.2 \\
\hline Daily energy intake (kJ/mouse) & ND & ND & $47 \cdot 7$ & 0.8 & $48 \cdot 1$ & 0.4 \\
\hline Body weight (g) & $27 \cdot 5$ & 0.4 & $28 \cdot 6$ & 0.6 & $29 \cdot 7$ & 0.7 \\
\hline Absolute weight gain (g) & ND & ND & $2 \cdot 2$ & 0.1 & 1.9 & 0.2 \\
\hline Liver weight & 1.5 & 0.1 & 1.5 & 0.0 & 1.5 & 0.0 \\
\hline Liver:body weight ratio (\%) & 5.4 & 0.2 & 5.4 & $0 \cdot 1$ & $5 \cdot 1$ & 0.1 \\
\hline Fasting blood glucose (mg/dl) & ND & ND & $133 \cdot 8$ & $7 \cdot 3$ & $119 \cdot 3$ & 5.0 \\
\hline Fasting insulin concentration (mU/l) & ND & ND & $10 \cdot 7$ & $2 \cdot 0$ & $9 \cdot 8$ & 1.3 \\
\hline HOMA-IR & ND & ND & 3.6 & 0.8 & 2.9 & 0.4 \\
\hline CCL-2 mRNA expression (-fold expression) & $2 \cdot 8$ & 0.3 & 4.9 & 0.4 & $1 \cdot 8^{\star}$ & 0.4 \\
\hline TNF- $a$ (ng/mg protein) & 0.23 & 0.04 & 0.43 & 0.02 & $0.29^{\star}$ & 0.02 \\
\hline PAl-1 (ng/mg protein) & 0.19 & 0.02 & 0.36 & 0.12 & 0.13 & 0.02 \\
\hline
\end{tabular}

FD, fructose-enriched liquid diet; SoB, sodium butyrate; CCL-2, chemokine (C-C motif) ligand 2; HOMA-IR, homoeostasis model assessment of insulin resistance; PAl-1, plasminogen activator inhibitor 1.

* Mean value was analysed by $t$ test significantly different from that of the FD group: $P<0.05$. 
(a)

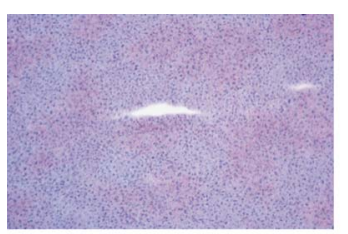

(b)

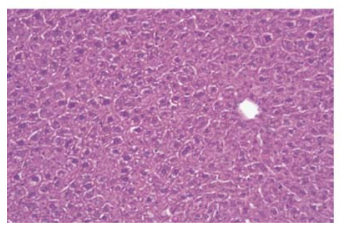

Control

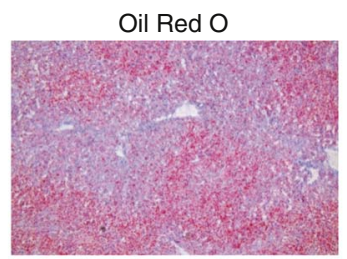

Hematoxylin-eosin

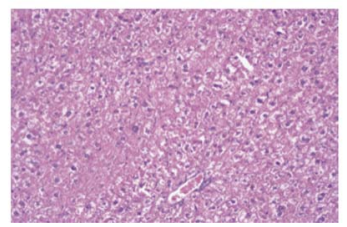

FD
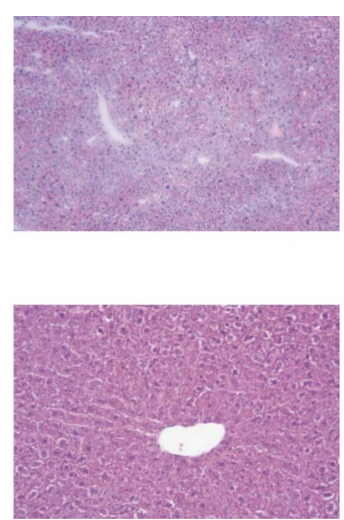

FD+SoB (c)

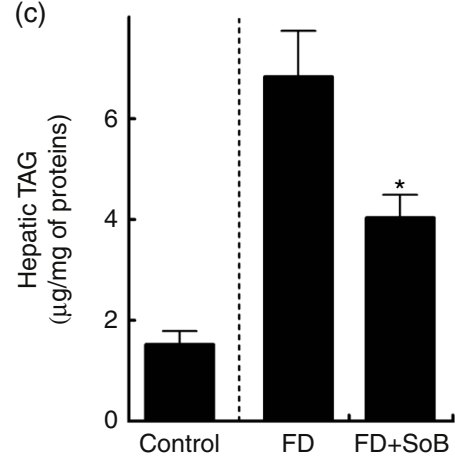

(e)

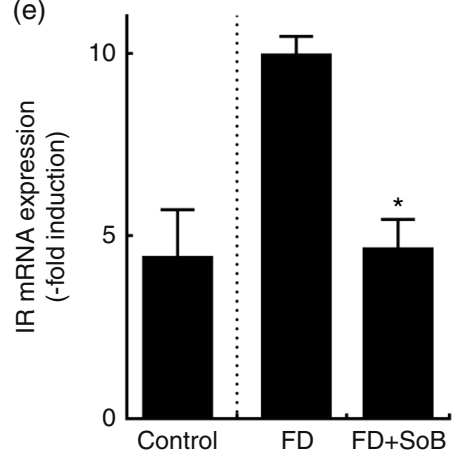

(d)

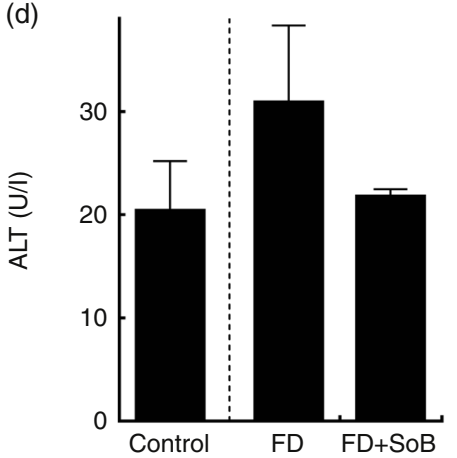

(f)

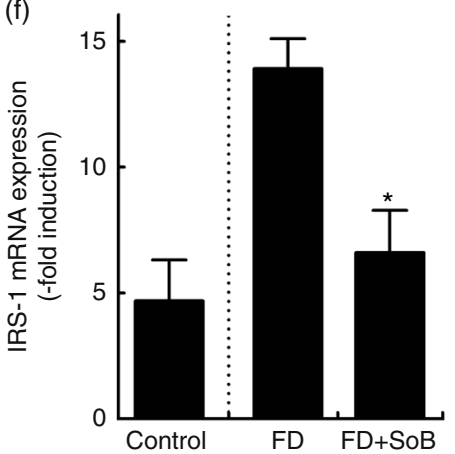

Fig. 1. Effect of a chronic supplementation of sodium butyrate (SoB) on lipid accumulation and markers of inflammation in livers of fructose-fed mice. Representative photomicrographs of (a) Oil red O staining (100x) and (b) haematoxylin-eosin staining (200x) of liver sections. Red colour in Oil red O staining indicates fat, whereas in haematoxylin-eosin stained tissue sections fat is displayed as 'white' droplets, as fat dissolved during embedding of tissue. (c) Quantitative analysis of hepatic TAG content. (d) Alanine aminotransferase (ALT) activity in plasma. Expression of (e) insulin receptor (IR) and (f) insulin receptor substrate (IRS)-1 mRNA in liver tissue of mice. Values are means with standard errors represented by vertical bars. FD, fructose-enriched liquid diet. ${ }^{*} P<0.05$ between FD- and FD+SoB-fed groups as determined using $t$ test.

Protein concentration of hydroxyindole-O-methyltransferase and melatonin in duodenum, as well as expression of melatonin receptor-1 $m R N A$ in liver

Protein levels of HIOMT in duodenum of mice fed FD + SoB were significantly higher than those of mice fed only FD (Fig. 5(a) and online Supplementary Fig. S1(d)). In line with the HIOMT protein levels, concentration of melatonin in duodenum was also significantly higher in duodenum of mice fed $\mathrm{FD}+\mathrm{SoB}$ when compared with mice only fed FD (Fig. 5(b)). Furthermore, MT-1 mRNA expression in livers of mice fed FD + SoB was significantly higher when compared with those only fed FD (Fig. 5(c)).
Expression of hydroxyindole-O-methyltransferase and melatonin receptor-2 mRNA and melatonin protein levels in differentiated human carcinoma colon-2 cells treated with sodium butyrate and expression of melatonin receptor-1/-2 and inducible nitric oxide synthase $m R N A$, as well as nitrate concentration in lipopolysaccharidechallenged J774A.1 concomitantly treated with melatonin

To further delineate the effect of SoB on melatonin synthesis in enterocytes, differentiated Caco- 2 cells being a model of small intestinal enterocytes ${ }^{(24)}$ were incubated with SoB for 6-48 h. 
(a)

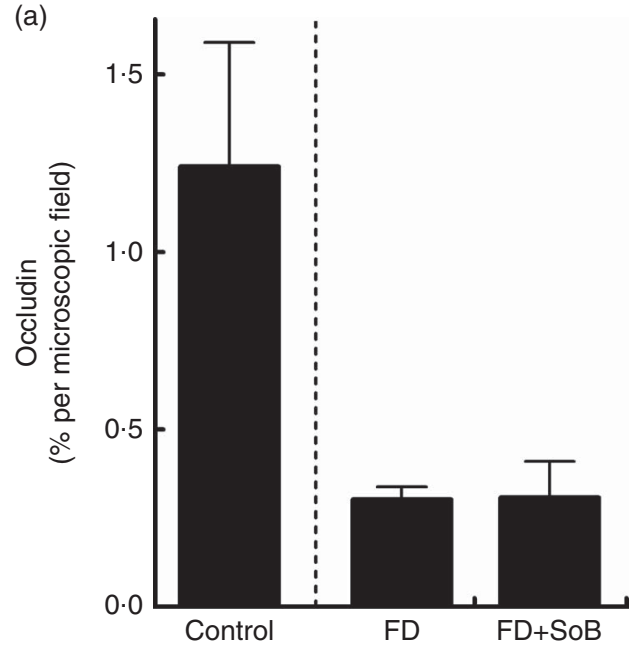

(b)

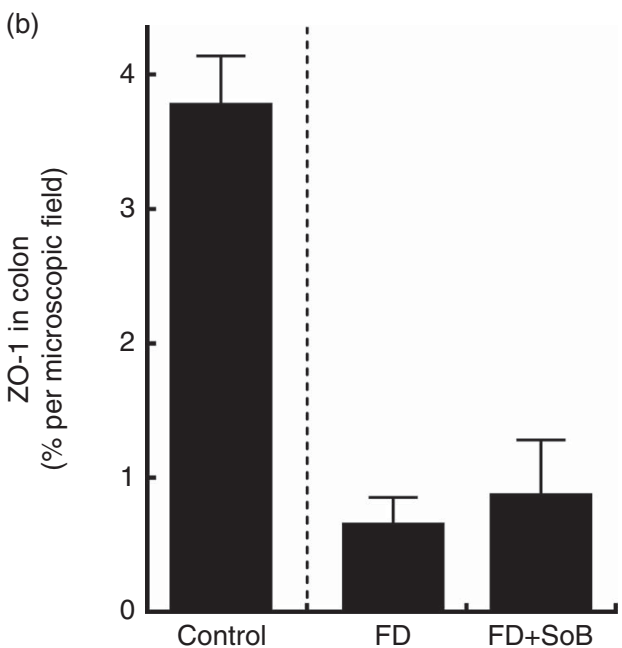

(c)

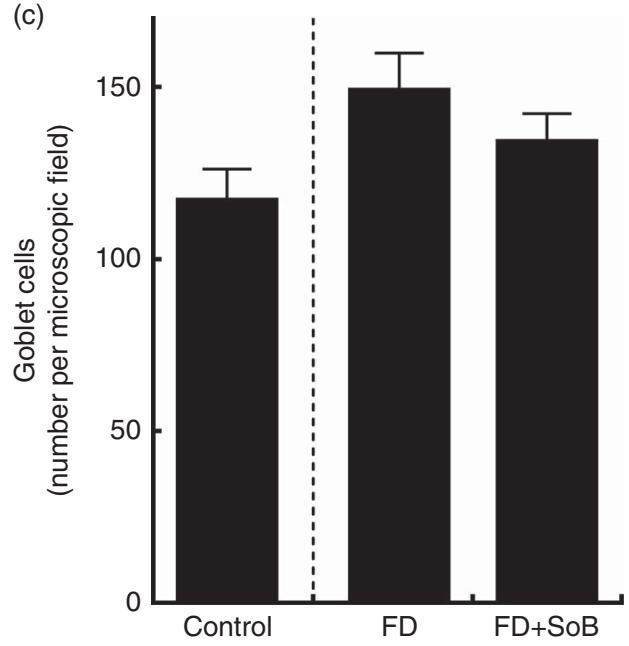

Fig. 2. Effect of a chronic supplementation of sodium butyrate (SoB) on markers of intestinal barrier function. Densitometric analysis of (a) occludin and (b) zonula occludens 1 (ZO-1) protein staining in the duodenum. (c) Number of goblet cells in the duodenum per microscopic field. Values are means with standard errors represented by vertical bars. FD, fructose-enriched liquid diet.
Treatment with 3 or $6 \mathrm{~mm}-\mathrm{SoB}$ did not change the HIOMT or MT-2 mRNA expression in Caco-2 cells after $6 \mathrm{~h}$. However, expressions of both HIOMT and MT-2 mRNA were significantly induced in Caco- 2 cells incubated with $3 \mathrm{~mm}-\mathrm{SoB}$ when compared with naïve controls after $24 \mathrm{~h}$, whereas in cells incubated with 6 mm-SoB a similar effect was not found (Fig. 6(a) and (b)). Expression of MT-1 mRNA in Caco-2 cells was below the level of detection at all time points and SoB concentrations used. In line with the findings for HIOMT and $M T-2$, melatonin concentration in the medium also increased in a time- and dosedependent manner, with levels being significantly higher in media of cells incubated with $6 \mathrm{~mm}-\mathrm{SoB}$ after $24 \mathrm{~h}$ when compared with naïve cells (Fig. 6(c)). After $48 \mathrm{~h}$, melatonin concentration in media of cells treated with 3 or $6 \mathrm{~mm}-\mathrm{SoB}$ was also higher than in naïve controls; however, differences did not reach the level of significance $(P=0 \cdot 31)$ (Fig. 6(c)).

To determine whether melatonin has a protective effect on LPS-induced activation of Kupffer cells, J774A.1 cells being a model of Kupffer cells ${ }^{(25)}$ were challenged with LPS after a 2-h pre-incubation with melatonin. Expressions of both $M T-1$ and MT-2 mRNA were significantly induced in LPS-challenged J774A.1 cells preincubated with melatonin (Fig. 7(a) and (b)). While melatonin had no effect on iNOS mRNA expression or nitrate concentration in naïve J774A.1 cells, LPS-dependent induction of $i N O S$ mRNA and increase of nitrate in the cell culture medium were significantly suppressed in cells concomitantly treated with melatonin (Fig. 7(c) and (d)).

\section{Discussion}

In the present study, despite receiving $0.6 \mathrm{~g} / \mathrm{kg}$ body weight per $\mathrm{d}$ SoB in their diet, butyrate levels in portal plasma were similar among groups. It has been shown before by others that treating rodents and chicken, respectively, with a bolus dose of SoB resulted in a rapid increase in butyrate plasma levels; however, in these studies, doses of SoB were markedly higher than in the present study ( $5 v \cdot 0.6 \mathrm{~g} / \mathrm{kg}$ body weight) and SoB was administered as a bolus once by gavage or intraingluvial, whereas in the present study mice received SoB chronically with their liquid diet ${ }^{(26,27)}$. Nevertheless, in mice fed FD supplemented with SoB, hepatic fat accumulation was markedly attenuated when compared with FD-fed mice. Furthermore, plasma ALT activity and markers of inflammation such as $C C L-2$ and TNF- $\alpha$, but also PAI-1, of these mice were almost at the level of naïve controls. These data are in line with our own previous findings in mice fed a WSD supplemented with SoB but also with those of others ${ }^{(9,11,14,28)}$. Furthermore, also in line with our own findings but also those of others ${ }^{(9,11,14,28)}$, the protective effects of the $\mathrm{SoB}$ supplementation against the development of NAFLD were associated with a protection against the down-regulation of genes involved in insulin signalling in the liver - for example mRNA expression of $I R$ and $I R S$-1. However, as the dietary feeding model used in the present study only induces early changes associated with the development of NAFLD and metabolic diseases, fasting glucose and insulin levels, as well as HOMA index, were not yet found to be altered between groups. Indeed, it has been shown before 
(a)

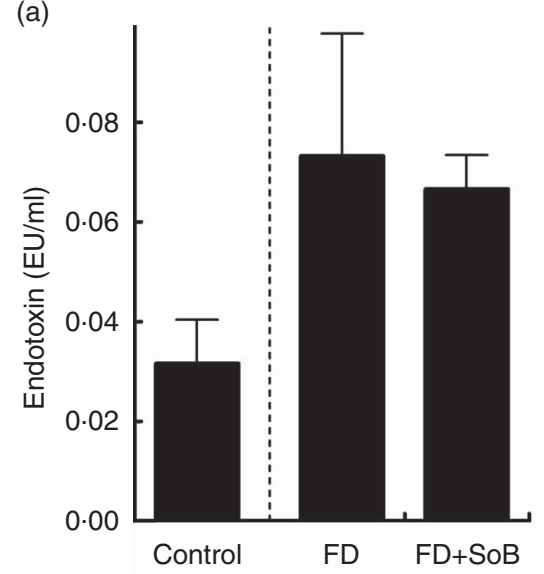

(c)

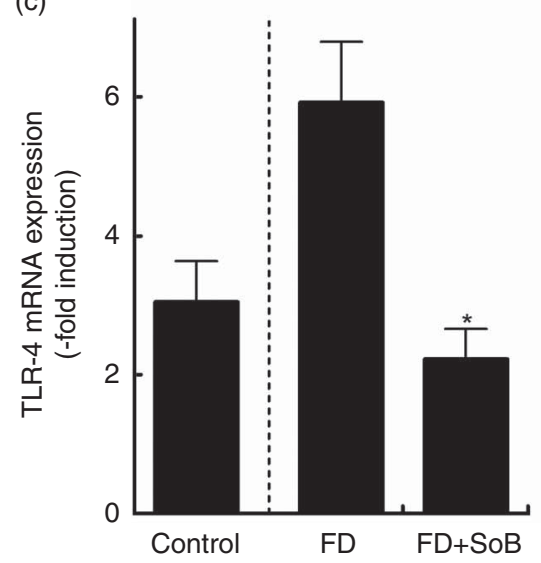

(b)

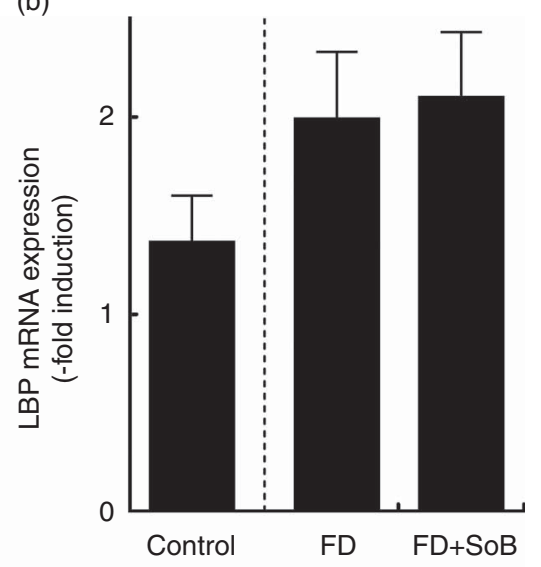

(d)

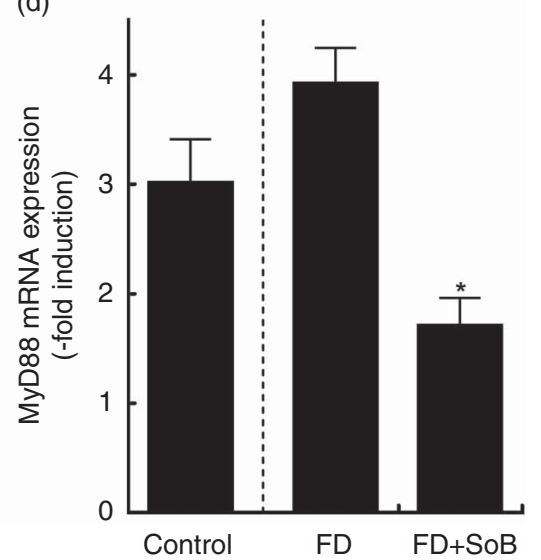

Fig. 3. Effect of a chronic supplementation of sodium butyrate (SoB) on endotoxin levels in portal plasma and mRNA expression of lipopolysaccharide-binding protein $(L B P)$, toll-like receptor $4(T L R-4)$ and myeloid differentiation primary response $88(M y D 88)$ in liver tissue of mice. (a) Endotoxin concentration in portal plasma. Expression of (b) $L B P$, (c) TLR-4 and (d) MyD88 mRNA in livers of mice. Values are means with standard errors represented by vertical bars. FD, fructose-enriched liquid diet. ${ }^{*} P<0.05$ between FD- and FD+SoB-fed groups as determined using $t$ test.

in patients with NAFLD that despite not yet displaying pathologically altered fasting glucose and insulin levels, markers of hepatic insulin signalling like IRS-1 mRNA were markedly lower than in controls ${ }^{(29)}$. Taken together, these data further bolster the hypothesis that an oral supplementation of SoB may protect mice from the onset of NAFLD and hepatic insulin resistance.

Results of several studies suggest that butyrate may be a critical factor in maintaining intestinal homoeostasis ${ }^{(30)}$. Indeed, results of in vitro, as well as in vivo, studies suggest that butyrate may at least in part exert its beneficial effects in intestinal homoeostasis through increasing intestinal integrity and modulation of tight-junction proteins ${ }^{(9,13,31)}$. Furthermore, both a loss of tight-junction proteins in the upper parts of the small intestine and increased plasma levels of endotoxin and expression of $L B P$ mRNA have repeatedly been associated with the development of NAFLD ${ }^{(9)}$. However, in line with previous findings ${ }^{(14)}$, in the present study mice fed the FD fortified with SoB were neither protected from the loss of the tight-junction proteins occludin and ZO-1 nor showed altered numbers of goblet cells in duodenum. In the present study, markers of intestinal barrier function such as tight-junction proteins were only determined in the upper parts of the small intestine.
Therefore, it cannot be ruled out that SoB might also affect lower parts of the intestine, thereby adding to the effects observed in the present study. However, in line with the results of tight-junction protein levels, concentration of bacterial endotoxin in portal vein and expression of $L B P$ mRNA in the liver shown to strongly correlate with bacterial endotoxin levels $^{(32,33)}$ were also similar between the FD groups. Results of animal, as well as human, studies further suggest that an induction of the TLR-4-signalling cascade in the liver may be critical in the development of NAFLD ${ }^{(22,29,34-36)}$. Indeed, Rivera et al. ${ }^{(35)}$ but also our own group ${ }^{(36)}$ showed that TLR-4-mutant $(\mathrm{C} 3 \mathrm{H} / \mathrm{HeJ})$ mice were markedly protected from the development of NAFLD. In the present study, the marked inductions of $T L R-4$ expression but also of its adaptor protein $M y D 88$ found in FD-fed mice when compared with naïve controls were almost completely attenuated by the supplementation of SoB. Furthermore, expression of iNOS protein, also shown before to be highly regulated through endotoxin- and TLR-4-dependent mechanisms in the liver ${ }^{(37)}$, and concentration of 4-HNE, as well as SOD-1 activity, mediating the clearance of superoxide anion to hydrogen peroxide ${ }^{(38)}$, were also only induced in livers of mice fed FD when compared with naïve controls. This effect of 
(a)

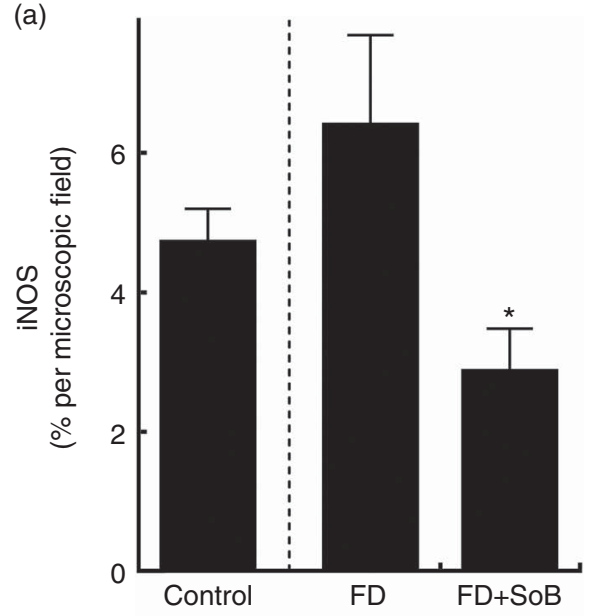

(b)

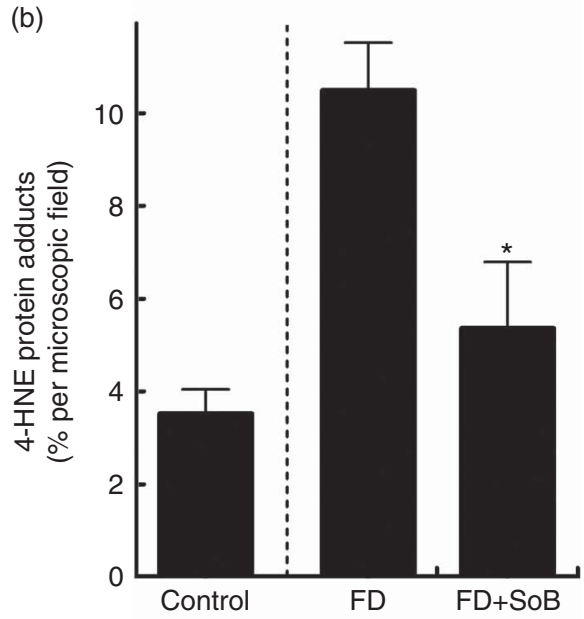

(c)

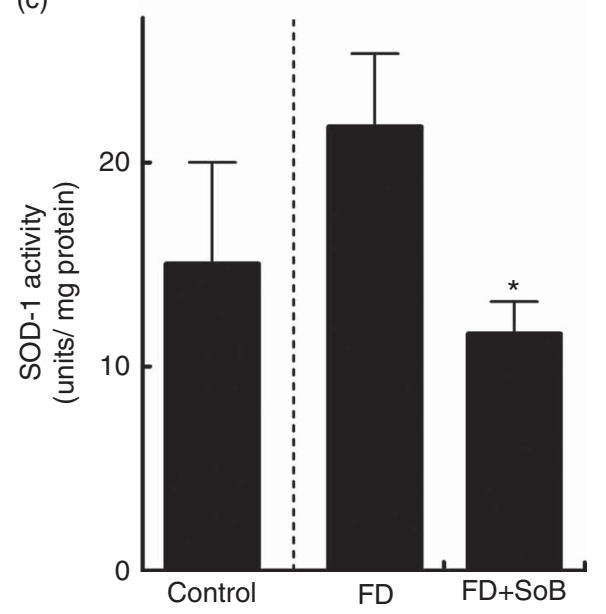

Fig. 4. Effect of a chronic supplementation of sodium butyrate (SoB) on markers of lipid peroxidation and oxidative stress in the liver tissue of mice. Densitometric analysis of immunostaining of (a) inducible nitric oxide synthase (iNOS) and (b) 4-hydroxynonenal (4-HNE) protein adducts in liver (c) Superoxide dismutase-1 (SOD-1) activity in the liver tissue of mice. Values are means with standard errors represented by vertical bars. FD, fructose-enriched liquid diet. ${ }^{\star} P<0.05$ between FD- and FD + SoB-fed groups as determined using $t$ test.
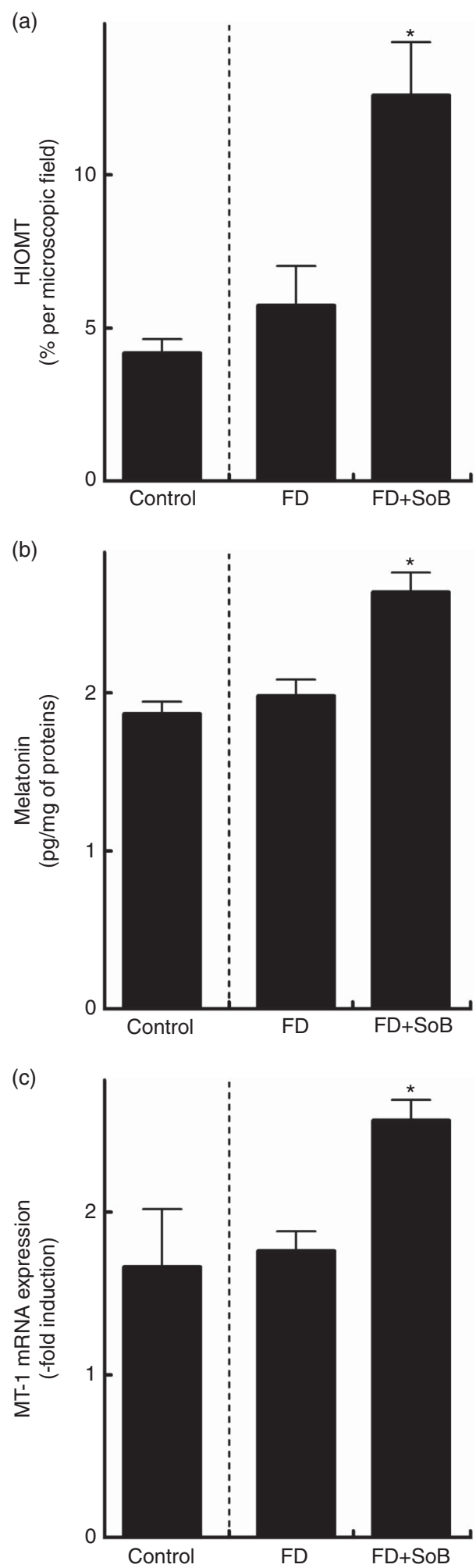

Fig. 5. Effect of chronic supplementation of sodium butyrate (SoB) on hydroxyindole-O-methyltransferase (HIOMT) protein levels and melatonin concentration in duodenum, as well as mRNA expression of melatonin receptor (MT)-1 in liver of fructose-fed mice. (a) Densitometric analysis of HIOMT staining in duodenal sections and (b) melatonin concentration in duodenum of mice. (c) Expression of MT-1 mRNA in the liver of mice. Values are means with their standard errors represented by vertical bars. FD, fructose-enriched liquid diet. ${ }^{\star} P<0.05$ between FD- and FD + SoB-fed groups as determined using $t$ test. 
(a)

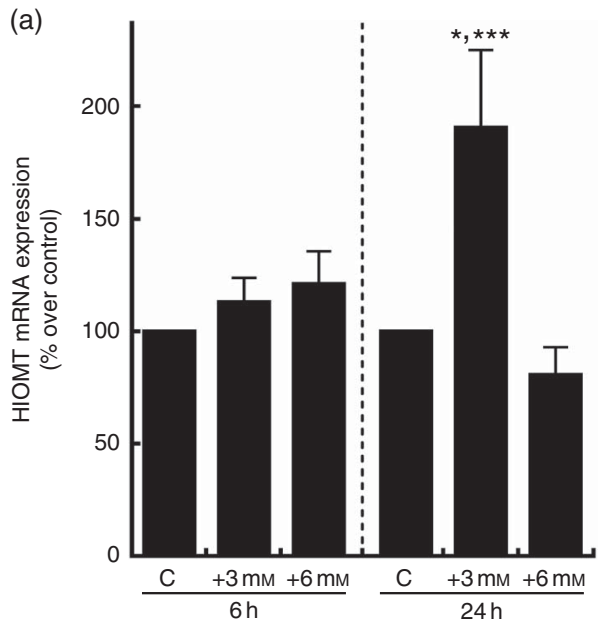

(b)
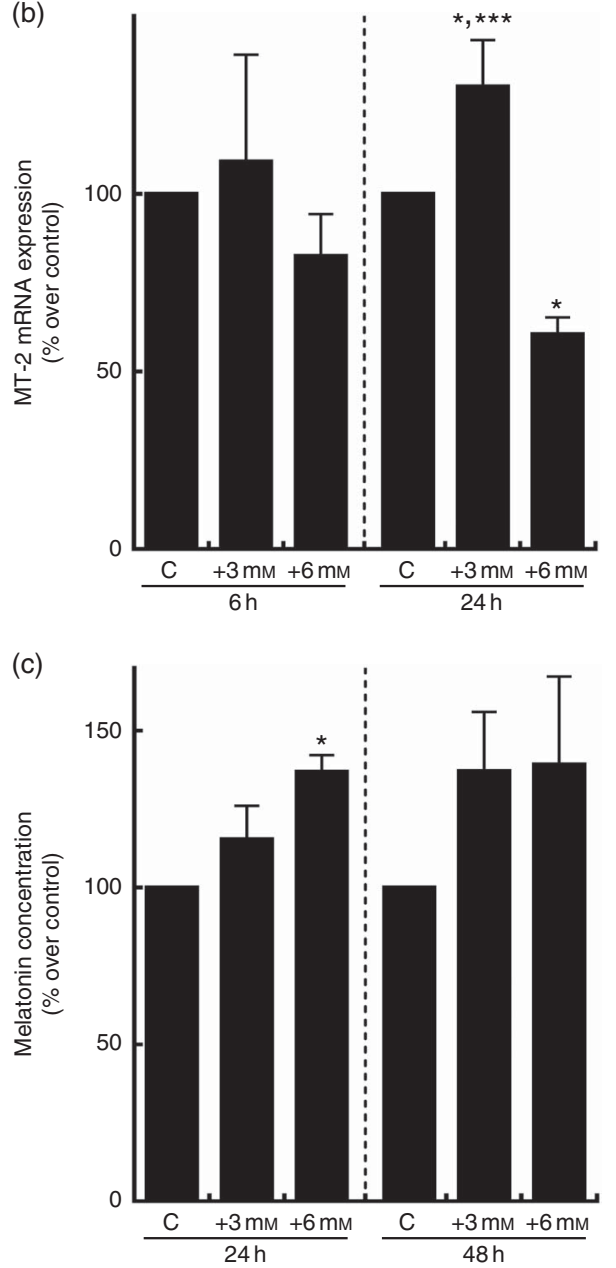

Fig. 6. Effect of sodium butyrate (SoB) on hydroxyindole-O-methyltransferase (HIOMT) and melatonin receptor (MT)-2 mRNA expression, as well as melatonin concentration, in human carcinoma colon-2 (Caco-2) cells. Expression of (a) HIOMT and (b) MT-2 mRNA in differentiated Caco-2 cells 6 or $24 \mathrm{~h}$ after incubation with $0-6 \mathrm{mM}-\mathrm{SoB}$. (c) Melatonin concentration in medium of differentiated Caco-2 cells 24 or $48 \mathrm{~h}$ after incubation with $0-6 \mathrm{~mm}$ SoB. One-way ANOVA with Tukey's post hoc test was used for statistical analysis of data. Values are means with their standard errors represented by vertical bars. $\mathrm{C}$, control group. ${ }^{*} P<0.05$ compared with the group of Caco-2 cells without treatment for $24 \mathrm{~h} ;{ }^{* \star \star} P<0.05$ compared with the group of Caco-2 cells treated with $6 \mathrm{~mm}-\mathrm{SoB}$ for $24 \mathrm{~h}$. the diet was almost completely attenuated in livers of mice fed FD supplemented with SoB. The latter findings are contrary to those of others showing that the anti-inflammatory effects of $\mathrm{SoB}$ in a rat model of myocardial ischaemia/reperfusion were associated with a protection against the loss of SOD ${ }^{(39)}$. However, in these studies, SoB was administered intraperitoneally to rats, whereas in the present study mice were fed SoB with their diet. Mechanisms involved in the effects of SoB on SOD-1 activity in livers of mice fed a FD remain to be determined. Mattace et $a l^{(11)}$ also found that the protective effects of the supplementation of butyrate against the development of NAFLD induced by feeding a high-fat diet were associated with a protection against the induction of TLR-4 and iNOS expression in the liver. However, while in previous studies of our own group SoB-feeding was also associated with an attenuation of $i N O S$ induction in the liver, TLR- 4 expression in livers was unchanged ${ }^{(14)}$. Differences between the two feeding experiments might have resulted from differences in composition of diets fed, for example a WSD rich in fructose but also fat and cholesterol $v$. a standard diet enriched with fructose in the present study. Taken together, results of the present study but also from previous studies of our own and other groups $^{(11,14)}$ suggest that supplementation of butyrate may protect rodents from the development of liver damage through mechanisms involving a suppression of the induction of TLR-4 and subsequent signalling cascades in the liver. Indeed, butyrate has been suggested to directly alter enzymatic systems involved in oxidative defenses ${ }^{(24)}$. However, as butyrate levels in portal vein were similar among all groups, the molecular mechanism involved in the antioxidative effects of SoB in the present study seems not to have resulted primarily from a direct effect of SoB on the liver but rather through indirect mechanisms (see below).

Results of older in vitro studies suggest that butyrate may modulate expression of enzymes involved in synthesis of melatonin ${ }^{(40)}$. Indeed, it has been reported by Deng et al. ${ }^{(41)}$ that in cultured Y79 human retinoblastoma cells treatment with $3 \mathrm{~mm}-\mathrm{SoB}$ for $3 \mathrm{~d}$ markedly increased the release of melatonin. Furthermore, both HIOMT and arylalkylamine $\mathrm{N}$-acetyltransferase have been shown to be expressed in enterochromaffin cells but also in enterocytes in the small intestine ${ }^{(42,43)}$, suggesting that melatonin may also be synthesised from its precursor serotonin in the small intestine. In the present study, oral supplementation of SoB was associated with a significant induction of HIOMT and melatonin protein levels in the duodenum. In support of the findings that SoB may alter synthesis of melatonin in enterocytes, we showed that incubation of differentiated Caco- 2 cells with SoB resulted in a marked time- and dose-dependent induction of HIOMT and MT-2 mRNA expression and melatonin release from these cells. Indeed, in the present study, melatonin receptors were shown to be induced in the presence of melatonin (see Fig. 7), suggesting that melatonin itself might regulate MT-1 and MT-2 expressions. The apparent discrepancy of the expression of HIOMT and melatonin levels found in Caco-2 cells at the different time points might have resulted from the different detection levels - for example mRNA expression and protein levels. In addition, it could be that as bioavailability of SoB 
(a)

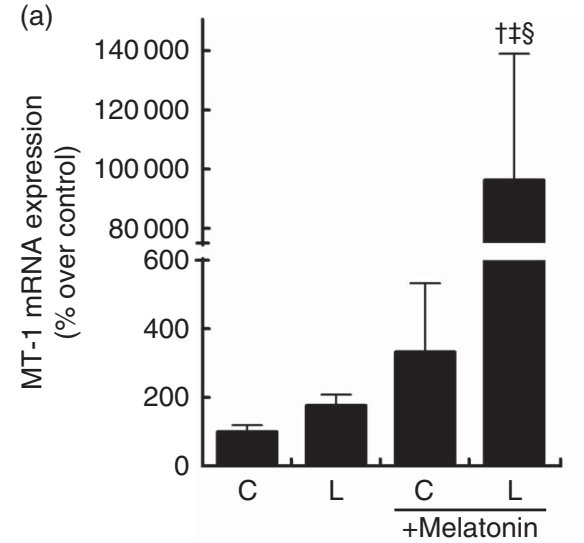

(c)

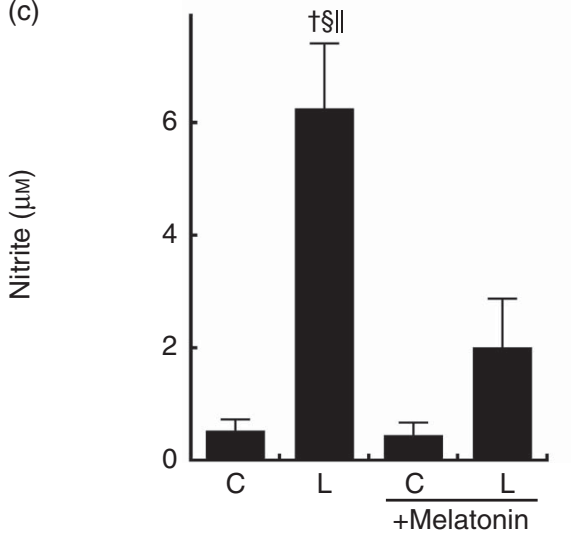

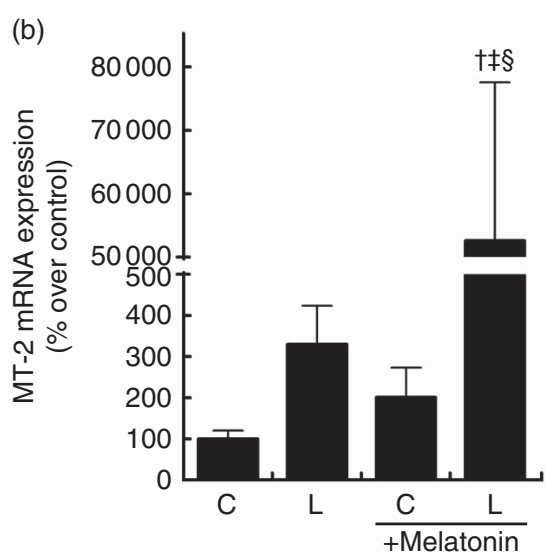

(d)

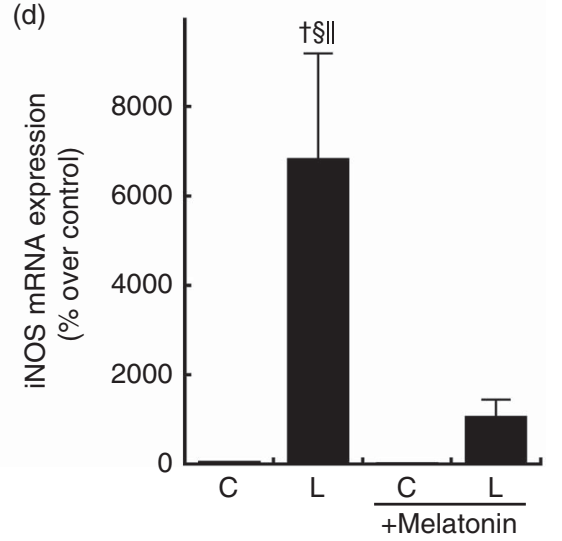

Fig. 7. Effect of melatonin on mRNA expression of melatonin receptors (MT), lipopolysaccharide (LPS)-induced inducible nitric oxide synthase (iNOS) and nitrite concentration in J774A.1 macrophages. Expression of (a) MT-1, (b) MT-2 and (d) iNOS MRNA in the J774A.1 macrophages pretreated with melatonin and challenged with LPS and (c) nitrite concentration in media of these cells. One-way ANOVA with Tukey's post hoc test was used for statistical analysis of data. Values are means with standard errors represented by vertical bars. C, control group; L, LPS-treated group. ${ }^{\dagger} P<0.05$ compared with control group without treatment; ${ }^{\ddagger} P<0.05$ compared with LPS-treated group; ${ }^{\S} P<0.05$ compared with melatonin-pre-incubated control group; $P<0.05$ compared with melatonin-pre-incubated and LPS-treated group.

decreased with time this might have affected the expression of HIOMT. This needs to be addressed in future studies. Melatonin has been shown to possess marked antioxidative capacities $^{(44,45)}$. Indeed, results of animal studies suggest that beneficial effects of melatonin in various settings of liver damage were associated with an attenuation of oxidative and inflammatory damage associated with these diseases ${ }^{(46,47)}$. It has been shown that treatment with melatonin but also its precursor tryptophan reduced levels of pro-inflammatory cytokines and improved parameters of fat metabolism in patients with NAFLD ${ }^{(48)}$. Furthermore, Hatzis et al. $^{(47)}$ showed that the protective effects of melatonin treatment in vivo against high-fat diet-induced liver disease were associated with an attenuation of peroxidation and oxidative stress in liver tissue. In the present study, the increased levels of HIOMT and melatonin in the upper parts of the small intestine were associated with a significant induction of $M T-1$ in the liver but also a marked attenuation of lipid peroxidation and iNOS protein levels. In support of the hypothesis that in the present study the increased synthesis of melatonin in the small intestine of mice might have modulated endotoxin-dependent Kupffer cell-mediated response in the liver, both mRNA expression of iNOS and formation of nitrate were markedly attenuated in LPS-challenged
J774A.1 cells when cells were concomitantly treated with melatonin. Furthermore, also somewhat supporting this hypothesis, expressions of $M T-1$ and $M T-2$ were also significantly induced in cells treated with melatonin. The slight induction of $M T-1$ and the even more pronounced induction of MT-2 found in J774A.1 cells treated only with LPS might have resulted from an LPS-dependent induction of melatonin synthesis in these cells. Indeed, results of a recent in vitro study suggest that enzymes involved in the synthesis of melatonin in macrophages are strongly regulated through LPS- and NF- $\kappa \mathrm{B}-$ dependent signalling cascades ${ }^{(49)}$. Taken together, these data suggest that supplementation of SoB may increase melatonin synthesis in enterocytes in the small intestine, which in turn, probably through MT-dependent signalling cascades, attenuated the induction of $i N O S$ and lipid peroxidation in the liver. However, molecular mechanisms underlying the induction of intestinal melatonin synthesis, as well as pathways involved in the effects of melatonin on the liver, remain to be determined.

\section{Conclusion}

In summary, results of the present study are in line with previous findings showing that an oral supplementation of SoB 
has protective effects on the development of $\operatorname{NAFLD}^{(9,11,14)}$. Our results suggest that these effects do not result from a protection against the enhanced intestinal permeability and translocation of bacterial endotoxins associated with the development of NAFLD. Rather, our results suggest that a supplementation of SoB enhances intestinal melatonin synthesis and subsequently attenuates the endotoxin-dependent induction of $i N O S$ and formation of reactive oxygen species in the liver. However, molecular mechanisms involved in the SoBdependent modulation of intestinal melatonin synthesis and the effects of melatonin on iNOS in the liver need to be determined in future studies. Furthermore, future studies will have to delineate whether similar beneficial effects of an oral supplementation of SoB are also found in humans.

\section{Acknowledgements}

The project was funded in part by grants from the Federal Ministry of Education and Research and the German Research Society (BMBF, FKZ: 03105084 and 01KU1214A and DFG: BE2376/4-2 all to I. B.).

The contribution of each author was as follows: I. B. designed the research; C. J. J., A. J. E., C. S., D. Z., M. L., G. K., H. L. and M. S. conducted the research; C. J. J. and D. Z. analysed the data; C. J. J. and I. B. wrote the paper; I. B. had primary responsibility for the final content.

There are no conflicts of interest.

\section{Supplementary material}

For supplementary material/s referred to in this article, please visit https://doi.org/10.1017/S0007114516004025

\section{References}

1. Blachier M, Leleu H, Peck-Radosavljevic M, et al. (2013) The burden of liver disease in Europe: a review of available epidemiological data. J Hepatol 58, 593-608.

2. Hashimoto E, Tokushige K \& Ludwig J (2015) Diagnosis and classification of non-alcoholic fatty liver disease and nonalcoholic steatohepatitis: current concepts and remaining challenges. Hepatol Res 45, 20-28.

3. Tilg H \& Moschen AR (2010) Evolution of inflammation in nonalcoholic fatty liver disease: the multiple parallel hits hypothesis. Hepatology 52, 1836-1846.

4. Dyson J \& Day C (2014) Treatment of non-alcoholic fatty liver disease. Dig Dis 32, 597-604.

5. Miele L, Valenza V, La TG, et al. (2009) Increased intestinal permeability and tight junction alterations in nonalcoholic fatty liver disease. Hepatology 49, 1877-1887.

6. Thuy S, Ladurner R, Volynets V, et al. (2008) Nonalcoholic fatty liver disease in humans is associated with increased plasma endotoxin and plasminogen activator inhibitor 1 concentrations and with fructose intake. J Nutr 138, $1452-1455$.

7. Volynets V, Kuper MA, Strahl S, et al. (2012) Nutrition, intestinal permeability, and blood ethanol levels are altered in patients with nonalcoholic fatty liver disease (NAFLD). Dig Dis Sci 57, 1932-1941.
8. Berni CR, Di CM \& Leone L (2012) The epigenetic effects of butyrate: potential therapeutic implications for clinical practice. Clin Epigenetics $\mathbf{4}, 4$.

9. Endo H, Niioka M, Kobayashi N, et al. (2013) Butyrateproducing probiotics reduce nonalcoholic fatty liver disease progression in rats: new insight into the probiotics for the gutliver axis. PLOS ONE 8, e63388.

10. Liu B, Qian J, Wang Q, et al. (2014) Butyrate protects rat liver against total hepatic ischemia reperfusion injury with bowel congestion. PLOS ONE 9, e106184.

11. Mattace RG, Simeoli R, Russo R, et al. (2013) Effects of sodium butyrate and its synthetic amide derivative on liver inflammation and glucose tolerance in an animal model of steatosis induced by high fat diet. PLOS ONE 8, e68626.

12. Yang F, Wang LK, Li X, et al. (2014) Sodium butyrate protects against toxin-induced acute liver failure in rats. Hepatobiliary Pancreat Dis Int 13, 309-315.

13. Wang HB, Wang PY, Wang X, et al. (2012) Butyrate enhances intestinal epithelial barrier function via up-regulation of tight junction protein Claudin-1 transcription. Dig Dis Sci $\mathbf{5 7}$, 3126-3135.

14. Jin CJ, Sellmann C, Engstler AJ, et al. (2015) Supplementation of sodium butyrate protects mice from the development of non-alcoholic steatohepatitis (NASH). Br J Nutr 114, 1745-1755.

15. Sellmann C, Jin CJ, Degen C, et al. (2015) Oral glutamine supplementation protects female mice from nonalcoholic steatohepatitis. J Nutr 145, 2280-2286.

16. Sellmann C, Jin CJ, Engstler AJ, et al. (2016) Oral citrulline supplementation protects female mice from the development of non-alcoholic fatty liver disease (NAFLD). Eur $J \mathrm{Nutr}$ (epublication ahead of print version 5 August 2016).

17. Spruss A, Kanuri G, Stahl C, et al. (2012) Metformin protects against the development of fructose-induced steatosis in mice: role of the intestinal barrier function. Lab Invest $\mathbf{9 2}$, 1020-1032.

18. Pelaseyed T, Bergstrom JH, Gustafsson JK, et al. (2014) The mucus and mucins of the goblet cells and enterocytes provide the first defense line of the gastrointestinal tract and interact with the immune system. Immunol Rev 260, 8-20.

19. Bergheim I, Guo L, Davis MA, et al. (2006) Critical role of plasminogen activator inhibitor-1 in cholestatic liver injury and fibrosis. J Pharmacol Exp Ther 316, 592-600.

20. Haub S, Kanuri G, Volynets V, et al. (2010) Serotonin reuptake transporter (SERT) plays a critical role in the onset of fructoseinduced hepatic steatosis in mice. Am J Physiol Gastrointest Liver Physiol 298, G335-G344.

21. Jin CJ, Engstler AJ, Ziegenhardt D, et al. (2016) Loss of lipopolysaccharide-binding protein attenuates the development of diet-induced non-alcoholic fatty liver disease (NAFLD) in mice. J Gastroenterol Hepatol (epublication ahead of print version 12 July 2016).

22. Wagnerberger S, Spruss A, Kanuri G, et al. (2012) Toll-like receptors 1-9 are elevated in livers with fructose-induced hepatic steatosis. Br J Nutr 107, 1727-1738.

23. Nazih H, Nazih-Sanderson F, Krempf M, et al. (2001) Butyrate stimulates ApoA-IV-containing lipoprotein secretion in differentiated Caco-2 cells: role in cholesterol efflux. J Cell Biochem 83, 230-238.

24. Russo I, Luciani A, De CP, et al. (2012) Butyrate attenuates lipopolysaccharide-induced inflammation in intestinal cells and Crohn's mucosa through modulation of antioxidant defense machinery. PLOS ONE 7, e32841.

25. Kheder RK, Hobkirk J \& Stover CM (2016) In vitro modulation of the LPS-induced proinflammatory profile of hepatocytes and macrophages- approaches for intervention in obesity? Front Cell Dev Biol 4, 61. 
26. Egorin MJ, Yuan ZM, Sentz DL, et al. (1999) Plasma pharmacokinetics of butyrate after intravenous administration of sodium butyrate or oral administration of tributyrin or sodium butyrate to mice and rats. Cancer Chemother Pharmacol $\mathbf{4 3}$, 445-453.

27. Matis G, Kulcsar A, Turowski V, et al. (2015) Effects of oral butyrate application on insulin signaling in various tissues of chickens. Domest Anim Endocrinol 50, 26-31.

28. Vinolo MA, Rodrigues HG, Festuccia WT, et al. (2012) Tributyrin attenuates obesity-associated inflammation and insulin resistance in high-fat-fed mice. Am J Physiol Endocrinol Metab 303, E272-E282.

29. Kanuri G, Ladurner R, Skibovskaya J, et al. (2015) Expression of toll-like receptors 1-5 but not TLR 6-10 is elevated in livers of patients with non-alcoholic fatty liver disease. Liver Int $\mathbf{3 5}$ 562-568.

30. Leonel AJ \& Alvarez-Leite JI (2012) Butyrate: implications for intestinal function. Curr Opin Clin Nutr Metab Care 15, 474-479.

31. Ma X, Fan PX, Li LS, et al. (2012) Butyrate promotes the recovering of intestinal wound healing through its positive effect on the tight junctions. J Anim Sci 90, Suppl. 4, 266-268.

32. Douhara A, Moriya K, Yoshiji H, et al. (2015) Reduction of endotoxin attenuates liver fibrosis through suppression of hepatic stellate cell activation and remission of intestinal permeability in a rat non-alcoholic steatohepatitis model. Mol Med Rep 11, 1693-1700.

33. Zuo G, He S, Liu C, et al. (2002) [Expression of lipopolysaccharide binding protein and lipopolysaccharide receptor CD14 in experimental alcoholic liver disease]. Zhonghua Gan Zang Bing Za Zhi 10, 207-210.

34. Csak T, Pillai A, Ganz M, et al. (2014) Both bone marrowderived and non-bone marrow-derived cells contribute to AIM2 and NLRP3 inflammasome activation in a MyD88dependent manner in dietary steatohepatitis. Liver Int 34, 1402-1413.

35. Rivera CA, Adegboyega P, van RN, et al. (2007) Toll-like receptor-4 signaling and Kupffer cells play pivotal roles in the pathogenesis of non-alcoholic steatohepatitis. J Hepatol $\mathbf{4 7}$, 571-579.

36. Spruss A, Kanuri G, Wagnerberger S, et al. (2009) Toll-like receptor 4 is involved in the development of fructose-induced hepatic steatosis in mice. Hepatology 50, 1094-1104.
37. Spruss A, Kanuri G, Uebel K, et al. (2011) Role of the inducible nitric oxide synthase in the onset of fructose-induced steatosis in mice. Antioxid Redox Signal 14, 2121-2135.

38. Zhu JH, Zhang X, Roneker CA, et al. (2008) Role of copper, zinc-superoxide dismutase in catalyzing nitrotyrosine formation in murine liver. Free Radic Biol Med 45, 611-618.

39. Hu X, Zhang K, Xu C, et al. (2014) Anti-inflammatory effect of sodium butyrate preconditioning during myocardial ischemia/ reperfusion. Exp Ther Med 8, 229-232.

40. Wiechmann AF \& Burden MA (1999) Regulation of AA-NAT and HIOMT gene expression by butyrate and cyclic AMP in Y79 human retinoblastoma cells. I Pineal Res 27, 116-121.

41. Deng MH, Lopez G-C, Lynch HJ, et al. (1991) Melatonin and its precursors in Y79 human retinoblastoma cells: effect of sodium butyrate. Brain Res 561, 274-278.

42. Konturek SJ, Konturek PC, Brzozowski T, et al. (2007) Role of melatonin in upper gastrointestinal tract. J Physiol Pharmacol 58, Suppl. 6, 23-52.

43. Al-Ghoul WM, Abu-Shaqra S, Park BG, et al. (2010) Melatonin plays a protective role in postburn rodent gut pathophysiology. Int J Biol Sci 6, 282-293.

44. Zhang HM \& Zhang Y (2014) Melatonin: a well-documented antioxidant with conditional pro-oxidant actions. J Pineal Res 57, 131-146

45. Manchester LC, Coto-Montes A, Boga JA, et al. (2015) Melatonin: an ancient molecule that makes oxygen metabolically tolerable. J Pineal Res 59, 403-419.

46. Sharma S \& Rana SV (2013) Melatonin improves liver function in benzene-treated rats. Arb Hig Rada Toksikol 64, 33-41.

47. Hatzis G, Ziakas P, Kavantzas N, et al. (2013) Melatonin attenuates high fat diet-induced fatty liver disease in rats. World J Hepatol 5, 160-169.

48. Celinski K, Konturek PC, Slomka M, et al. (2014) Effects of treatment with melatonin and tryptophan on liver enzymes, parameters of fat metabolism and plasma levels of cytokines in patients with non-alcoholic fatty liver disease -14 months follow up. J Physiol Pharmacol 65, 75-82.

49. Muxel SM, Laranjeira-Silva MF, Carvalho-Sousa CE, et al. (2016) The RelA/cRel nuclear factor-kappaB (NF-kappaB) dimer, crucial for inflammation resolution, mediates the transcription of the key enzyme in melatonin synthesis in RAW 264.7 macrophages. J Pineal Res 60, 394-404. 